\title{
Predicting the development of early reading in Chinese-Dutch bilinguals
}

\author{
Han Yuan ${ }^{1,2}$ (I) $\cdot$ Eliane Segers ${ }^{1,2} \cdot$ Ludo Verhoeven $^{1,2}$
}

Accepted: 20 July 2021 / Published online: 31 July 2021

(c) The Author(s) 2021

\begin{abstract}
The relationships between phonological awareness, rapid naming, short term verbal memory, letter knowledge, visual skills and word reading in kindergarten, and the predictive patterns from kindergarten to first grade were examined in $41 \mathrm{Chi}$ nese-Dutch bilingual children living in the Netherlands in both their first language (Chinese) and second language (Dutch). In kindergarten, Chinese word reading was predicted by Chinese phonological awareness, and Dutch word reading was predicted by Dutch phonological awareness and letter knowledge. There was a robust autoregressive effect of word reading from kindergarten to first grade in both Chinese and Dutch. Follow-up mediation analyses further showed that both phonological awareness in Chinese and phonological awareness combined with letter knowledge in Dutch in kindergarten had an indirect effect on Grade 1 word reading via kindergarten word reading. Although cross-language correlation was found in word reading for bilingual children in kindergarten, Dutch word reading did not add to the prediction of Chinese word reading when Chinese precursor measures were taken into account.
\end{abstract}

Keywords Chinese-Dutch bilingual children $\cdot$ Letter knowledge $\cdot$ Linguistic transfer $\cdot$ Phonological awareness $\cdot$ Reading development

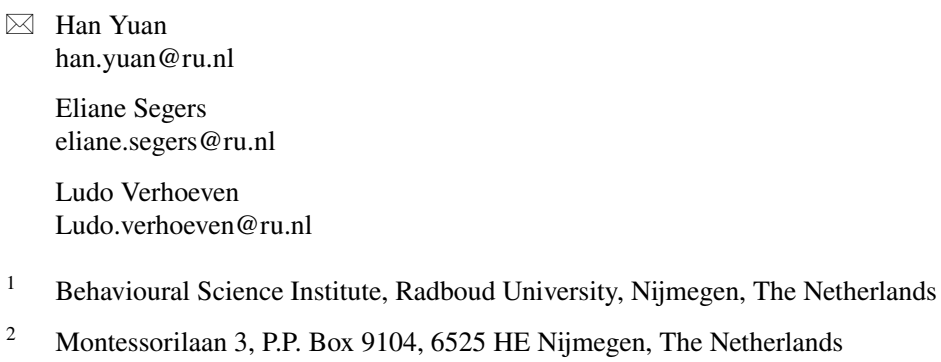




\section{Introduction}

The number of children learning a second language worldwide is increasing at a rapid speed. Previous research has shown the concurrent and longitudinal predictive relationships between cognitive-linguistic skills with reading performance, such as phonological processing skills (phonological awareness, rapid naming, and shortterm verbal memory) and letter knowledge among bilingual children who learned two alphabetic languages (e.g., Gottardo \& Lafrance, 2005; Swanson et al., 2011) or a nonalphabetic first language (Chinese) along with an alphabetic language (e.g., Cheung et al., 2010; Lin et al., 2018; Wang et al., 2014a). These studies have also shown linguistic interdependence via transfer effects from one language to the other in learning to read (Dressler \& Kamil, 2006; Luo et al., 2014; Páez \& Rinaldi, 2006). However, longitudinal studies on bilingual Chinese children were only conducted within kindergarten or within primary school, leaving the contribution of these prereading predictors from kindergarten to early first and second language reading in first grade unclear. In addition, while visual skills were found to facilitate early Chinese reading (Luo et al., 2013; Yang et al., 2013), these have rarely been examined in bilingual Chinese children. To fill these gaps in research, the present study examined the contribution of cognitive-linguistic predictors of reading skills in kindergarten and first grade in bilingual children whose first language is logographic (Chinese) and the second language as a transparent alphabetic language (Dutch), in the Netherland. The transfer effect between reading skills in the two languages was also examined. The longitudinal design in the present study may help to identify prereading precursors affecting subsequent reading acquisition and suggest new approaches for identifying children who are at risk for reading problems.

Chinese is a "morpho-syllabic" language, each Chinese character corresponds to one syllable (Chen \& Pasquarella, 2017). Another striking feature of Chinese is that it is a tonal language. There are four different tones in Mandarin Chinese. The Chinese writing system is logographic. Most Chinese characters are compound characters with phonetic and semantic radicals. In contrast, Dutch is a consistent alphabetic language in which the basic sound unit is a phoneme that can map to a grapheme.

\section{Predictors of early literacy development}

Learning to read depends on the mastery of the principle that written letters represent the sounds of speech (Byrne \& Fielding-Barnsley, 1989). Based on this, phonological processing skills which make use of speech sound within a language (McBride-Chang et al., 2005) and letter knowledge which reflects the ability of grapheme-phoneme correspondences, are critical to reading. Three relevant phonological processing skills (phonological awareness, rapid automatized naming (RAN), and short-term verbal memory (STM) have been identified by previous research (Wagner \& Torgesen, 1987). Phonological awareness is the ability to identify and manipulate small sound units in spoken words (Patel et al., 2004). RAN is typically assessed by the speed to name serial displays of pictures, letters, and digits 
(Georgiou et al., 2008). STM refers to the ability to retain and reproduce verbal information (Swanson \& Ashbaker, 2000). The predictive role of phonological skills in reading performance in alphabetic scripts and the association between these skills has been shown by several meta-analyses (Araújo et al., 2015; Melby-Lervåg et al., 2012; Swanson et al., 2003). There is also strong evidence that letter knowledge is a powerful predictor of early reading skills across alphabetic scripts (e.g., Caravolas et al., 2019; Georgiou et al., 2012).

For learning to read nonalphabetic scripts, such as Chinese, phonological processing skills may also be important. Although phonemes are not represented in the Chinese writing system, each Chinese character reflects a syllable (McBride-Chang $\&$ Ho, 2000). Also, most Chinese characters consist of a phonetic and a semantic radical. Mapping oral Chinese to its graphic representation probably requires partial access to the phonology of spoken Chinese (Hu \& Catts, 1998). A meta-analysis on Chinese children suggested that phonological awareness and RAN were universal correlates of Chinese reading (Song et al., 2016). Awareness of different-sized psycholinguistic units has been proved to have a strong predictive effect on Chinese word reading (syllable awareness, see McBride-Chang et al., 2008; onset and rime awareness, see Li et al., 2012; tone awareness, see Shu et al., 2008). Associations between RAN, STM, and reading for monolingual Chinese children in concurrent and longitudinal designs have also been shown (Li et al., 2012; Wei et al., 2015; Xue et al., 2013; Yeung et al., 2011; Zhao et al., 2019). For example, the study of Li et al. (2012) showed that speeded number naming was a unique correlate of Chinese character recognition in kindergarteners. Yeung et al. (2011) found that rapid naming, but not phonological awareness, was a significant predictor of Chinese word reading among first graders. Xue et al. (2013) showed that STM contributed to Grade 4 character naming.

Although Chinese characters cannot be pronounced by using grapheme-phoneme correspondence rules, Pinyin instruction is used in Mainland China to help children to connect oral Chinese and printed symbols. Past research showed a positive association between Pinyin knowledge and Chinese reading (e.g., Li et al., 2016; Lin et al., 2010; Wang et al., 2014b). Pinyin letter-name knowledge uniquely explained Chinese word reading after controlling for age and IQ in kindergarten children in Mainland China (Wang et al., 2014b).

Visual skills could be another critical factor for learning to read. Visual skills refer to the perception and interpretation of visual forms (Gardner, 1996). Reading ability involves pairing symbols with spoken referents (McBride-Chang \& Kail, 2002). When children are in the earliest period of learning to read, they "read" by remembering selected visual features (Ehri, 2005). Visual processing skills in preschoolers could thus be a causal factor in subsequent reading acquisition (Franceschini et al., 2012).

Visual skills are particularly important for learning to read Chinese because Chinese orthography consists of thousands of visually complex characters (Luo et al., 2013). A meta-analysis showed that visual skills had a moderate correlation with Chinese reading acquisition (Yang et al., 2013). Concurrent studies also showed that visual skills were associated with children's character reading in kindergarten (Luo et al., 2013). Few studies have investigated the longitudinal effect of visual skills on 
reading ability in the early learning phases. McBride-Chang et al. (2005) followed children in Hong Kong and Mainland China within kindergarten for nine months. They found that visual spatial relationships, which captured children's abilities to distinguish directionality in line drawings, uniquely predicted later Chinese character recognition after controlling for age, vocabulary, syllable deletion, and speeded naming of pictures in children in Mainland China. Similarly, Tong et al. (2011) followed Hong Kong kindergarteners for two years and showed that visual spatial relationships independently predicted subsequent Chinese word reading.

\section{Predictors of early literacy development for bilingual children}

Previous studies have suggested that learning to read an L2 is highly similar to learning to read in a first language (August \& Shanahan, 2006; Indefrey, 2006). Several studies have explored the relationship between cognitive-linguistic skills and reading ability in bilingual children (e.g., Chiappe et al., 2007; Jongejan et al., 2007; Páez \& Rinaldi, 2006; Verhoeven et al., 2017). Páez and Rinaldi (2006) followed Spanish-English bilingual children from kindergarten to first grade to identify the factors of early word reading. English phonological awareness in kindergarten was found to be a significant predictor of English word reading in first grade. Chiappe et al. (2007) examined the roles of speech perception and phonological processing in reading and spelling acquisition for native and nonnative speakers of English in first grade. Phonological awareness was an important contributor to early literacy skills for children in both language groups.

The predictive patterns have also been examined in children speaking two languages that are structurally distant, such as in Chinese-English bilingual children in English speaking context or Chinese children learning English as a second language in China (Cheung et al., 2010; Chow et al., 2005; McBride-Chang \& Kail, 2002; McBride-Chang \& Suk-Han Ho, 2005; Pan et al., 2011; Wang et al., 2014a; Yang et al., 2019; Yeung \& Chan, 2013). Phonological awareness was found to uniquely predict word reading in L1 (e.g., Pan et al., 2011) and L2 (Cheung et al., 2010; Yeong et al., 2014; Yeung \& Chan, 2013). Wang et al., (2014a) followed ChineseEnglish children in a primary school in Washington and found that phonological awareness in Grade 1 predicted word reading in Grade 2 in L1 and L2. In contrast, Yang et al. (2019) followed Hong Kong first graders for 13-months and showed that L1 word reading in Grade 1 and Grade 2 were predicted by RAN, rather than by phonological awareness and STM. Chow et al. (2005), in a study following Hong Kong children learning English as a second language for 9-month in kindergarten, found that phonological awareness and RAN, but not STM, predicted word reading concurrently and longitudinally in L1.

As past studies have shown that these early literacy predictors were associated with word reading and its development in L1 and L2, and it has also been found that individual differences in children's early word reading prevail across grades for children (Gottardo \& Lafrance, 2005; Verhoeven \& van Leeuwe, 2012). It could expect that poor ability in literacy predictors may cause poor performance on word reading in kindergarten, which in turn leads to lower subsequent word reading ability. In 
other words, early literacy predictors may be important to subsequent word reading via its impact on concurrent word reading.

For bilingual children learning to read, one particular interest is to investigate whether the lexical constituent processes in one language can facilitate reading in another language. Cross-linguistic transfer is defined as "the use of linguistic knowledge of one language to leverage the learning of another language" (Yang et al., 2017, on page 3). A large amount of research has examined this cross-language transfer for bilinguals. For alphabetic languages, clear evidence for the association between L1 decoding and L2 decoding performance (Melby-Lervåg \& Lervåg, 2011; Swanson et al., 2004) and its growth (Páez \& Rinaldi, 2006; Pasquarella et al., 2015) has been found. Also, for languages that are distantly related, such as Chinese and English (e.g., Keung \& Ho, 2009; meta-analysis by Yang et al., 2017), such evidence was provided. Cross-language transfer was generally found to go from the stronger to the weaker language, and not the other way around (see Pasquarella et al., 2015).

Taken together, these findings on bilingual children suggested that similar precursors were found for learning to read L1 and L2. Significant interdependency was also shown in L1 and L2. However, the reviewed studies on Chinese bilingual children are limited within kindergarten or primary school and mainly focused on Chinese bilingual children with English, an opaque orthography as a second language. No study has examined the longitudinal predictive roles of such a huge wide of prereading cognitive-linguistic skills in subsequent word reading in Chinese bilingual children who speak Dutch, a more consistent orthography (Patel et al., 2004) as the second language from kindergarten to first grade.

\section{Present study}

The present study aimed to investigate the concurrent and longitudinal relationships between phonological processing skills (phonological awareness, RAN, and STM), letter knowledge, visual skills, and reading skills in bilingual children speaking Chinese (L1) and Dutch (L2) in kindergarten and first grade. The following research questions were addressed:

1. To what extent do early literacy variables in kindergarten (phonological processing skills, letter knowledge, and visual skills) predict Chinese and Dutch word reading in kindergarten and first grade and to what extent can the relationship between these early literacy variables and word reading in first grade be explained by word reading in kindergarten?

2. To what extent are L1 and L2 word reading associated and can word reading skills in the dominant language add to the prediction of word reading in the less proficient language in both kindergarten and first grade?

Concerning the first research question, regarding Chinese, we expected that word reading could primarily be explained by phonological awareness, Pinyin letter knowledge, and RAN. Based on the results of previous studies and considering 
that bilingual children may have less Chinese reading experience compared to their monolingual peers, we expected STM and visual skills to be less important predictors for kindergarten children. We further expected kindergarten Chinese phonological awareness, RAN, Pinyin letter-name knowledge and visual skills to predict word reading in first grade.

For Dutch, we expected phonological awareness, letter knowledge and RAN to predict word reading in kindergarten, while visual skills may be less related to Dutch word reading if the precursors are all considered in one model. We further expected RAN as a robust predictor of first-grade reading in Dutch, as it was suggested that kindergarten phonological awareness played a weak role in subsequent reading acquisition in consistent orthographies (De Jong \& Van der Leij, 1999) while RAN was argued to be a strong predictor of subsequent reading achievement in consistent orthographies (Wimmer et al., 2000).

Regarding the second research question, we expected that Chinese and Dutch word reading would be associated. Word reading in the dominant language was expected to predict word reading in the less proficient language after controlling for the linguistic skills in the less proficient language. In addition to the expectations regarding both research questions, we aimed to further explore possible relations between the variables under study, using mediation analyses.

\section{Method}

\section{Participants}

A sample of fifty-two typically developing Chinese-Dutch bilingual children were recruited from five Chinese Sunday schools in the Netherlands. Children attended Dutch classes in regular schools during the week and Chinese classes in Sunday schools on weekends. All the participants were first tested in their last year of kindergarten. One year later, they were tested again. Forty-one children (24 boys and 17 girls, $M_{\text {age }}=71.54$ months, $S D=4.21 ; M_{\mathrm{IQ}}=27.37, S D=4.63$ ) remained in the study for the second assessment; the other eleven participants had moved to another city in the Netherlands or to China. The standard vocabulary levels in Chinese $(M=78.63$, $S D=29.79)$ and Dutch $(M=90.63, S D=16.16)$ of bilingual children were tested by the Chinese Peabody Picture Vocabulary Test (Lu \& Liu, 1998) and Dutch version of the Peabody Picture Vocabulary Test-III-NL (Dunn et al., 2005). The scores were within the normal range and the compared standard scores showed that these children were more proficient in Dutch than in Chinese, $\mathrm{t}(40)=2.51, p<0.05, d=0.39$.

At the start of the study, parents' educational status and language exposure at home were measured by a parents' questionnaire. Five categories were used to determine the educational level $(1=$ primary education, $2=$ lower secondary education, $3=$ higher secondary education/vocational education, $4=$ higher education/college, $5=$ university). The average education level of the parents of the bilingual children was at an intermediate to higher level, $M=3.80, S D=1.13$.

Parents of the participants were asked to indicate to what extent their children spoke Dutch or Chinese with their family members (father, mother, siblings) on a 
five-point scale $(1=$ only Dutch, $2=$ mostly Dutch, $3=$ equal, $4=$ mostly Chinese, $5=$ only Chinese). We calculated the proportion of language exposure of each child by dividing their sum scores for the three items (family members) by the maximum scores. A higher score indicated a larger amount of Chinese exposure at home. The scores ranged from 0.20 to 1.00 ; the average was 0.66 which means Chinese was spoken a litter bit more than Dutch in the bilingual home.

\section{Measurements}

\section{Chinese word reading}

Chinese word reading was measured using a character recognition task in the study of Shu et al. (2008). It consisted of 60 single-character words which were listed in an increasing level of difficulty. Children were asked to read from the beginning and stopped after ten consecutive errors. The scores were the number of correct answers. The Cronbach's alpha of this task in Time 1 and 2 were 0.91 and 0.96 , respectively.

\section{Chinese phonological awareness}

Chinese phonological awareness was tested by three tasks: syllable awareness, onset-rhyme awareness and tone awareness.

Chinese syllable awareness (Shu et al., 2008) consisted of two practice items and 16 test items. In each item, children were asked to delete one syllable of the two-syllable word. Half of the words were real words whereas the other half were nonsense words. The Cronbach's alpha of this task was 0.87 .

Chinese onset-rhyme awareness task revised from the rime and onset detection tasks as described in the study of Shu et al. (2008). Two choices from which children were asked to select the correct one were extended to four choices in each item in the present version. As the low reliability was shown in their study, increasing the picture choices could eliminate elements of guessing and improve reliability. This task consisted of two practice items and twenty test items. In each item, children were presented with a picture and the corresponding character, which was followed by four characters with corresponding pictures. They were asked to choose the character that was rhymed or had the same onset with the target one among the four choices. The Cronbach's alpha of this task was 0.70.

Chinese tone awareness task was based on the tone detection task (Shu et al., 2008). This task had two practice items and ten test items. Children were asked if the two single-syllable characters in each item had the same tone or not. The rime was kept same across all the one-syllable words. The reliability of this task was 0.52.

Since we expected a high interrelationship among the three measures, a principal axis factor analysis was conducted on the three measures described above with oblique rotation (Muthén, Muthén, 2007). The Kaiser-Meyer-Olkin measure verified the adequacy for this analysis, $\mathrm{KMO}=0.66$, which were considered mediocre according to Hutcheson and Sofroniou (1999). One factor had eigenvalues over 
Kaiser's criterion of 1 and explained $60.84 \%$ of the variance. All analyses in the current study were conducted using the factor scores.

\section{Chinese letter knowledge}

Pinyin sound task was used to measure Pinyin letter knowledge. Forty-seven lowercase Pinyin letters were randomly arranged in rows on one card, and children were asked to name their sounds. Each item was scored as correct (1) or incorrect (0). The maximum score is 47 .

\section{Chinese RAN}

Rapid naming was measured by a rapid object naming test, which was developed based on the Dutch version of rapid word naming (Van den Bos \& Lutje Spelberg, 2007). It involved 50 pictures presented in an $5 \times 10$ array which included five pictures repeated in random order. The experimenter ensured that children knew the exact characters that represented the five objects before the task started. Then children were asked to name all the objects as quickly and accurately as possible in one minute. The number of the correctly named objects that the children gave was the final score. All the characters were chosen from the first grade textbooks and were familiar to children. Five Chinese characters: 脚([jiăo], feet), 鱼([yú], fish), 树 ([shù], tree), 伞([săn], umbrella) and 包([bāo], bag) were selected for Chinese rapid naming. The Cronbach's alpha of this task was 0.97 .

\section{Chinese STM}

Chinese short term verbal memory was developed and based on the Dutch word span task (van der Schuit et al., 2011). Seven characters were randomly ordered into different lengths of strings from two to seven. All of them were chosen from the first grade textbooks and were familiar to children. There were 12 strings in total in each task. Children were orally presented with each string and asked to repeat the string. The Cronbach's alpha of this task was 0.81 .

\section{Dutch word reading}

Dutch word reading was tested by Drie-Minuten-Test [Three-Minute-Test] (Verhoeven, 1995), which was a standardized Dutch test. For the present study, only card 1A was used because this corresponded with the kindergarten level. The card was made up of five columns with 30 words in each. Children were requested to read as many words as possible within 1 min accurately. The score was the amount of correctly read words. The Cronbach's alpha of this task was reported to be 0.90 (Moelands et al., 2003). 


\section{Dutch phonological awareness}

Dutch phonological awareness was tested by four tasks: syllable awareness, rhyme awareness, begin phoneme isolation and phoneme segmentation.

Dutch syllable awareness was tested by the syllable synthesis task in which children were asked to synthesize words by combining separate syllables (Verhoeven, 2011). This task consisted of 20 words of increasing difficulty (from twoto four-syllable words). Children had to synthesize the words presented by the experimenter in syllables into complete words. Test administration ended when children could not synthesize five consecutive words. The reliability of this task was 0.95 .

Dutch rhyme awareness was tested by the rhyme awareness task (Verhoeven \& Van Kuyk, 1991) which consisted of two practice items and ten test items. In each item, children were asked to select the picture with a character that rhymed with the auditorily presented target stimulus. An example practice item was "Tas [Bag], Raam [Window], Kast [Closet], Maan [Moon], wat rijmt op Das [Scarf]?". The reliability of this task was 0.87 .

Dutch begin phoneme isolation was measured by the task of phoneme isolation (Schaars et al., 2017). Children were asked to sound out the first phoneme of the words. This task consisted of two practice items and ten test items. The test stopped when children made five consecutive errors. The reliability of this task was 0.92 .

Dutch phoneme segmentation was tested by phoneme segmentation task (Schaars et al., 2017). In this task, children were asked to orally present all the phonemes of the word in each item. The reliability of this task was 0.91 .

A high interrelationship was expected between the four Dutch phonological awareness tasks. A principal axis factoring was conducted on the four tasks. The Kaiser-Meyer-Olkin measure verified the adequacy for this analysis, $\mathrm{KMO}=0.76$ (Middling, according to Hutcheson \& Sofroniou, 1999). One factor had eigenvalues over Kaiser's criterion of 1 and explained $70.61 \%$ of the variance. Factor scores were used in all analyses in the present study.

\section{Dutch RAN}

The Dutch version of rapid object naming (Van den Bos \& Lutje Spelberg, 2007) was used to measure Dutch rapid naming task The testing process was similar to Chinese RAN. The five characters were Fiets (bicycle), eend (duck), boom (tree), schaar (scissors), stoel (chair). The Cronbach's alpha of this task was 0.98 .

\section{Dutch STM}

Dutch short term verbal memory was tested using Dutch word span task (van der Schuit et al., 2011). The testing process is similar to Chinese STM. The Cronbach's alpha of this task was 0.73 . 


\section{Dutch letter knowledge}

Dutch letter sound task was used to test children's Dutch letter knowledge. Thirtysix lower-case Dutch letters were randomly arranged into three rows in one hard card and children were asked to name the sounds of all the letters on the card as fast and accurately as possible.

\section{Visual skills}

The visual discrimination and visual spatial relationships subtests from Gardner's (1996) Test of Visual-perceptual skills-Revised were administered to test children's visual skills. Each task consisted of one practice item and 16 test items. In the visual discrimination task, children were asked to select the form (e.g., that matched the exact characteristics of the target one among five choices (e.g., 38 . In the visual spatial relationships task, children were required to indicate the figure that was oriented differently from the other four

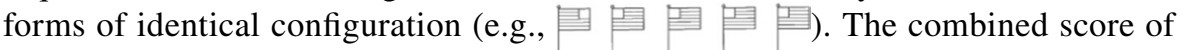
the two subtests was used in the present study, and the maximum score was 32 . The Cronbach's alpha of this task was 0.89 .

\section{Procedure}

A consent form from the parents and the Sunday schools was obtained, and convenient testing time was arranged individually for each child. Children were tested on the measures in kindergarten and again, one year later. Two of the experimenters were native Mandarin Chinese speakers and the other six were native Dutch speakers. All the measures testing in kindergarten took about $120 \mathrm{~min}$ in total for each participant. In Grade 1, reading tasks in Chinese and Dutch were conducted, taking about 35-40 min for each child.

\section{Analytical approach}

To answer the research questions, hierarchical regression analyses were conducted to find out to what extent word reading could be predicted by phonological awareness, RAN, STM, Pinyin knowledge, and visual skills in Chinese and Dutch. In the hierarchical regression, the first step contained the precursor measures (i.e., PA, letter knowledge, RAN, STM, and visual skills). As these were all included at the same time, there was no "order". When predicting growth, we corrected for the autoregressor, by first including word reading in kindergarten.

Further meditation analyses were conducted to explore the relationship between kindergarten literacy variables, word reading in kindergarten and first grade. In the mediation analyses, significant predictors in the hierarchical analyses were included as the independent variables. 
When examining cross-language prediction, we performed hierarchical regression analyses to determine whether word reading in the dominant language contributes to word reading in the less proficient language. Based on a comparison of vocabulary scores (see Participants section), Dutch was the dominant language, and hence Chinses word reading was the dependent variable when answering the second research question.

\section{Results}

\section{Descriptive statistics}

Means, standard deviations, ranges, skewness and kurtosis for all the measurements are displayed in Table 1. Table 2 presents the correlations among all the measures. With regard to the relationship between variables within kindergarten in Chinese, word reading significantly correlated with all the measures except for Pinyin

Table 1 Descriptive statistics $(\mathrm{N}=41)$ of all the measures in Chinese and Dutch in kindergarten and word reading in first grade

\begin{tabular}{|c|c|c|c|c|c|c|}
\hline & $M$ & $S D$ & Range & Skewness & Kurtosis & \\
\hline $\begin{array}{l}\text { Visual skills } \\
\text { (Kindergarten) }\end{array}$ & & 23.63 & 5.98 & $9-32$ & -.79 & -.20 \\
\hline \multicolumn{7}{|l|}{ L1 (Chinese) } \\
\hline \multirow[t]{8}{*}{ Kindergarten } & Phonological awareness & & & & & \\
\hline & Syllable awareness & 13.54 & 3.37 & $3-16$ & -1.96 & 3.57 \\
\hline & Onset-Rhyme awareness & 11.63 & 3.58 & $0-19$ & -.49 & 1.86 \\
\hline & Tone awareness & 6.05 & 2.00 & $0-9$ & -1.10 & 2.49 \\
\hline & Pinyin knowledge & 1.46 & 5.17 & $0-30$ & 4.74 & 24.47 \\
\hline & RAN & 27.07 & 12.91 & $0-50$ & -.24 & -.87 \\
\hline & STM & 6.88 & 1.87 & $0-10$ & -.85 & 1.26 \\
\hline & Word reading $(\mathrm{K})$ & 7.90 & 8.71 & $0-34$ & 1.91 & 2.91 \\
\hline Grade 1 & Word reading (G1) & 16.39 & 12.41 & $1-45$ & .44 & -.97 \\
\hline \multicolumn{7}{|l|}{ L2 (Dutch) } \\
\hline \multirow[t]{9}{*}{ Kindergarten } & Phonological awareness & & & & & \\
\hline & Syllable awareness & 16.88 & 5.30 & $0-20$ & -2.42 & 5.11 \\
\hline & Beginphoneme isolation & 7.44 & 3.18 & $0-10$ & -1.31 & .60 \\
\hline & Rhyme awareness & 8.49 & 2.45 & $0-10$ & -1.95 & 3.39 \\
\hline & Phoneme segmentation & 3.61 & 3.42 & $0-10$ & .51 & -1.07 \\
\hline & Letter knowledge & 18.12 & 9.86 & $0-36$ & .08 & -.90 \\
\hline & RAN & 41.59 & 11.84 & $0-50$ & -2.30 & 5.99 \\
\hline & STM & 4.02 & 1.48 & $0-7$ & -.24 & .56 \\
\hline & Word reading $(\mathrm{K})$ & 6.76 & 12.38 & $0-68$ & 3.59 & 15.19 \\
\hline Grade 1 & Word reading (G1) & 57.85 & 26.62 & 9-109 & .11 & -.62 \\
\hline
\end{tabular}




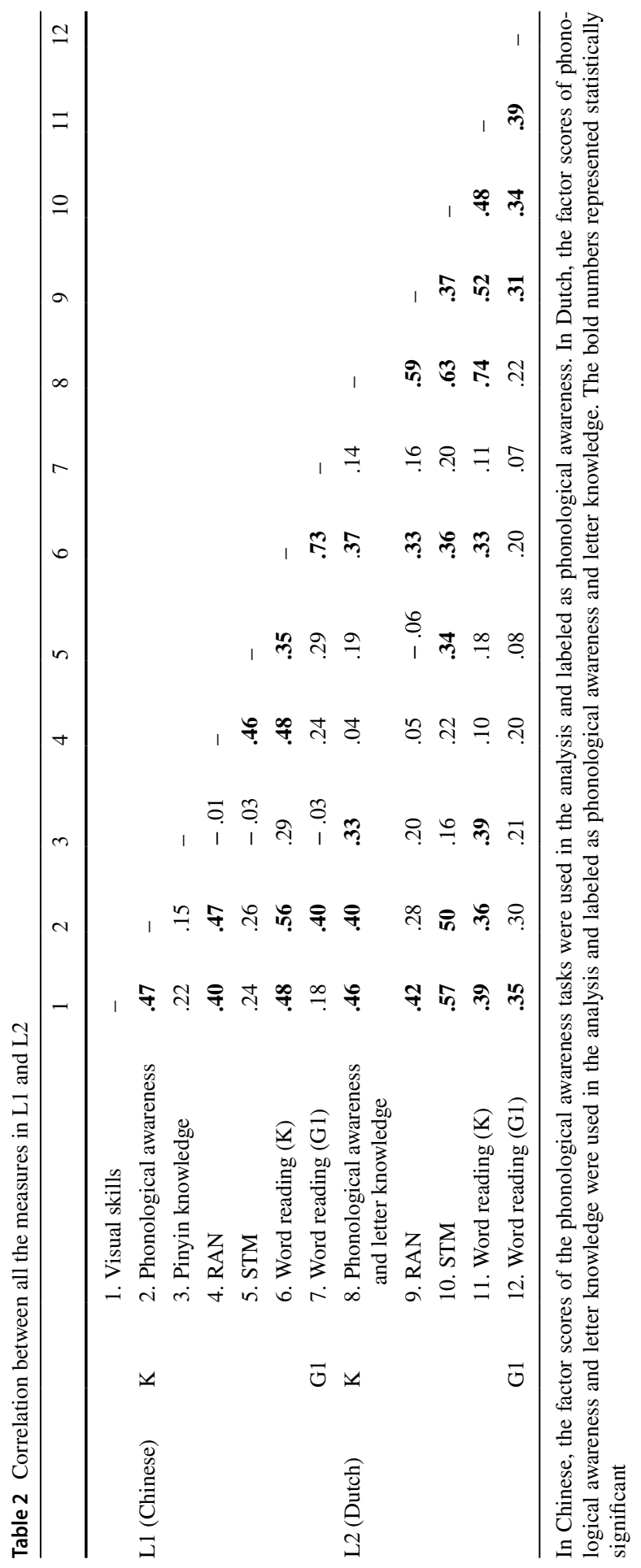


knowledge. Chinese word reading in Grade 1 significantly correlated with phonological awareness and word reading in kindergarten but did not correlate with any other variables.

With regard to the relationship between all the variables in Dutch, considering the high correlation between Dutch phonological awareness and letter knowledge $(\mathrm{r}=0.71)$, a principal axis factoring was conducted on the phonological awareness and the letter knowledge tasks. The Kaiser-Meyer-Olkin measure verified the adequacy for this analysis, $\mathrm{KMO}=0.81$ (Meritorious, according to Hutcheson \& Sofroniou, 1999). One factor had eigenvalues over Kaiser's criterion of 1 and explained $60.90 \%$ of the variance. Factor scores were used in the following analyses. In kindergarten, word reading significantly correlated with all the measures. Dutch word reading in Grade 1 significantly correlated with RAN, STM, visual skills, and word reading in kindergarten but did not correlate with kindergarten phonological awareness and letter knowledge.

\section{Predicting Chinese reading ability}

We first examined to what extent Chinese word reading would be predicted by all the variables within kindergarten. A regression analysis was conducted with Chinese kindergarten word reading as the dependent variable, phonological processing skills and visual skills as the predictors. To preserve more power for the analyses, we did not include Pinyin knowledge in the model because it did not significantly correlate with Chinese kindergarten word reading. The model was significant, $\mathrm{R}_{\text {adj }}^{2}=0.36$, $F(4,36)=6.55, p<0.01$ (see Table 3 ). Phonological awareness uniquely predicted Chinese kindergarten word reading.

Next, we examined to what extent Grade 1 word reading could be predicted from kindergarten variables in Chinese. A regression analysis was conducted with Grade 1 Chinese word reading as the dependent variable, kindergarten phonological awareness, RAN, STM, and visual skills as the predictors. The model was not significant, $\mathrm{R}^{2}$ adj $=0.11, F(4,36)=2.25, p=0.08$ (see Table 3). However, the final beta weight for phonological awareness was significant. We next checked whether the effect would hold if we control for Chinese kindergarten word reading in the analysis. A hierarchical regression analysis thus was performed, with kindergarten word reading in step 1 , and the other predictors in step 2. Kindergarten word reading in the first step accounted for 53\% of the variance in Grade 1 word reading, $F(1,39)=43.62$, $p<0.01$. Adding the other variables in the second step did not significantly improve the model, $\Delta \mathrm{R}^{2}=0.06, F(4,35)=1.24, p=0.31$. In all, the results suggested a mediating role of kindergarten word reading in the relation between kindergarten phonological awareness and Grade 1 word reading.

We explored this relation by conducting a mediation analysis with kindergarten phonological awareness as the independent variable, Grade 1 word reading as the dependent variable and kindergarten word reading as the mediator, using the Process add-on in SPSS (Hayes, 2017). Bootstrapping was set at 5000 cycles. The total $\mathrm{R}^{2}$ of the model was $0.53, F(2,38)=21.25, p<0.001$. It showed kindergarten phonological awareness had an indirect effect on Grade 1 word reading via 
Table 3 Hierarchical regression explaining kindergarten and grade 1 word reading from kindergarten precursors in Chinese

\begin{tabular}{|c|c|c|c|c|c|c|}
\hline Step & Predictors (K) & $\Delta \mathrm{R}^{2}$ & Cohen's $\mathrm{f}^{2}$ & B & SE & $\beta$ \\
\hline \multicolumn{7}{|c|}{ Word reading $(\mathrm{K})$} \\
\hline \multirow[t]{4}{*}{1} & Phonological awareness & $.42 * * *$ & .72 & .28 & .13 & $.34 *$ \\
\hline & RAN & & & .01 & .01 & .18 \\
\hline & STM & & & .06 & .06 & .13 \\
\hline & Visual skills & & & .03 & .02 & .22 \\
\hline Total $\mathrm{R}^{2}$ adj & & & & & & $.36^{* * *}$ \\
\hline \multicolumn{7}{|c|}{ Word reading (G1) } \\
\hline \multirow[t]{4}{*}{1} & Phonological awareness & .20 & .25 & 4.65 & 2.24 & $.38^{*}$ \\
\hline & RAN & & & -.02 & .18 & -.02 \\
\hline & STM & & & 1.38 & 1.11 & .21 \\
\hline & Visual skills & & & -.08 & .36 & -.04 \\
\hline Total $\mathrm{R}^{2}$ adj & & & & & & .11 \\
\hline \multicolumn{7}{|c|}{ Word reading (G1) } \\
\hline 1 & Word reading $(\mathrm{K})$ & $.53^{* * *}$ & 1.13 & 10.97 & 1.66 & $.73^{* * *}$ \\
\hline \multirow[t]{5}{*}{2} & Word reading $(\mathrm{K})$ & .06 & .15 & 12.33 & 2.16 & $.82 * * *$ \\
\hline & Phonological awareness & & & 1.24 & 1.74 & .10 \\
\hline & RAN & & & -.16 & .13 & -.17 \\
\hline & STM & & & .71 & .82 & .11 \\
\hline & Visual skills & & & -.45 & .27 & -.22 \\
\hline Total $R^{2}$ adj & & & & & & $.53 * * *$ \\
\hline
\end{tabular}

$* p<.05 ; * * p<.01 ; * * * p<.001$

its effect on kindergarten word reading $(\mathrm{ab}=5.03, \mathrm{CI}=[2.72,7.21])$. While there was a significant total effect from kindergarten phonological awareness to Grade 1 word reading $(c=5.00, t(39)=2.75, p<0.01)$, the direct effect was no longer significant $\left(\mathrm{c}^{\prime}=-0.03, t(38)=1.85, p=0.98\right)$. Results are depicted in Fig. 1 , reporting unstandardized coefficients.

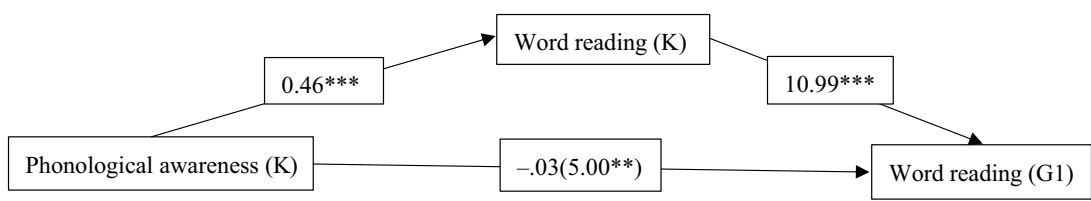

Fig. 1 Mediation model of kindergarten phonological awareness, kindergarten word reading, and grade 1 word reading in Chinese. The total effect (c) is between brackets, outside the brackets are the direct effects $\left(\mathrm{c}^{\prime}\right)$. The model is significant, $\mathrm{R}^{2}=.53, F(2,38)=21.25, p<.001$. The indirect effect of kindergarten phonological awareness on Grade 1 word reading via kindergarten word reading was 5.03, (CI $[2.72,7.21]) . * p<.05, * * p<.01, * * * p<.001$ 


\section{Predicting Dutch reading ability}

Then we examined to what extent Dutch word reading could be predicted by phonological awareness and letter knowledge, RAN, STM, and visual skills. We first examined to what extent Dutch word reading would be predicted by all the variables within kindergarten. A regression analysis was conducted with Dutch kindergarten word reading as the dependent variable, phonological awareness and letter knowledge, RAN, STM, and visual skills as the predictors. The model was significant, $\mathrm{R}^{2}{ }_{\text {adj }}=0.51, F(4,36)=11.47, p<0.001$ (see Table 4). Phonological awareness and letter knowledge uniquely predicted Dutch word reading in kindergarten.

Next, to what extent Dutch word reading in first grade could be predicted from kindergarten variables was examined. The model was not significant, $\mathrm{R}_{\text {adj }}^{2}=0.10$, $F(4,36)=2.06, p=0.11$. We checked whether the effect would hold if we control for Dutch kindergarten word reading in the analysis. Thus, a hierarchical regression analysis was performed with kindergarten word reading in step 1, and the other predictors in step 2. Kindergarten word reading in the first step accounted for $15 \%$ of

Table 4 Hierarchical regression explaining kindergarten and grade 1 word reading from kindergarten precursors in Dutch

\begin{tabular}{|c|c|c|c|c|c|c|}
\hline$\overline{\text { Step }}$ & Predictors (K) & $\Delta \mathrm{R}^{2}$ & Cohen's $\mathrm{f}^{2}$ & B & SE & $\beta$ \\
\hline \multicolumn{7}{|c|}{ Word reading $(\mathrm{K})$} \\
\hline \multirow[t]{4}{*}{1} & $\begin{array}{l}\text { Phonological awareness and letter knowl- } \\
\text { edge }\end{array}$ & $.56^{* * *}$ & 1.27 & 73 & .18 & $.65 * * *$ \\
\hline & RAN & & & .01 & .01 & .12 \\
\hline & STM & & & -.004 & .12 & -.005 \\
\hline & Visual skills & & & .01 & .03 & .04 \\
\hline Total $R^{2}$ adj & & & & & & $.51 * * *$ \\
\hline \multicolumn{7}{|c|}{ Word reading (G1) } \\
\hline \multirow[t]{4}{*}{1} & $\begin{array}{l}\text { Phonological awareness and letter knowl- } \\
\text { edge }\end{array}$ & .19 & .23 & -4.39 & 5.93 & -.17 \\
\hline & RAN & & & .54 & .43 & .24 \\
\hline & STM & & & 4.52 & 3.84 & .25 \\
\hline & Visual skills & & & .80 & .85 & .18 \\
\hline Total $R^{2}$ adj & & & & & & .10 \\
\hline \multicolumn{7}{|c|}{ Word reading (G1) } \\
\hline 1 & Word reading $(\mathrm{K})$ & $.15^{*}$ & .18 & 9.37 & 3.51 & $.39 *$ \\
\hline \multirow[t]{5}{*}{2} & Word reading $(\mathrm{K})$ & .12 & .16 & 10.84 & 5.17 & $.45^{*}$ \\
\hline & $\begin{array}{l}\text { Phonological awareness and letter knowl- } \\
\text { edge }\end{array}$ & & & -12.28 & 6.81 & -.46 \\
\hline & RAN & & & .42 & .42 & .19 \\
\hline & STM & & & 4.56 & 3.67 & .25 \\
\hline & Visual skills & & & .71 & .81 & .16 \\
\hline Total $R^{2}$ adj & & & & & & $.17^{*}$ \\
\hline
\end{tabular}


the variance in Grade 1 word reading, $F(1,39)=7.11, p<0.05$. Adding the other variables in the second step did not significantly improve the model, $\Delta \mathrm{R}^{2}=0.12, F$ $(4,35)=1.48, p=0.23$. In all, the results suggested a mediating role of kindergarten word reading in the relation between phonological awareness, letter knowledge and Grade 1 word reading.

We explored this relation by conducting a mediation analysis with the factor score of kindergarten phonological awareness and letter knowledge as the independent variable, Grade 1 word reading as the dependent variable and kindergarten word reading as the mediator, using the Process add-on in SPSS (Hayes, 2017). Bootstrapping was set at 5000 cycles (see Fig. 2). The total $\mathrm{R}^{2}$ of the model was $0.16, F(2$, $38)=3.78, p<0.05$. It showed that the factor score has an indirect effect on Grade 1 word reading via its effect on kindergarten word reading $(\mathrm{ab}=10.10, \mathrm{CI}=[1.29$, 22.31]). The total effect from kindergarten phonological awareness and letter knowledge to Grade 1 word reading $(c=5.79, t(39)=1.39, p=0.17)$ was not significant, the direct effect was not significant $\left(c^{\prime}=-4.31, t(38)=-0.73, p=0.47\right)$.

\section{Transfer of reading ability}

The second research question was to what extent L1 and L2 word reading were associated and whether word reading skills in the dominant language (i.e., Dutch) add to the prediction of word reading in the less proficient language (i.e., Chinese) in both kindergarten and first grade? We first examined within kindergarten, a hierarchical regression analysis was conducted with Chinese kindergarten word reading as the dependent variable, the Chinese kindergarten variables were entered in step 1, and Dutch kindergarten word reading in step 2 (see Table 5). Chinese kindergarten variables in the first step accounted for $42 \%$ of the variance in kindergarten word reading, $F(4,36)=6.55, p<0.001$. Adding Dutch kindergarten word reading in the second step did not significantly improve the model, $\Delta \mathrm{R}^{2}=0.01, F(1,35)=0.57, p=0.46$. Then we examined whether Dutch kindergarten word reading predicts Chinese word reading in first grade. A hierarchical regression analysis was conducted with Chinese Grade 1 word reading as the dependent variable, the Chinese kindergarten variables were entered in step 1, and Dutch kindergarten word reading in step 2. Chinese kindergarten variables in the first step accounted for $20 \%$ of the variance in kindergarten word reading, $F(4,36)=2.25, p=0.08$. Adding Dutch kindergarten word

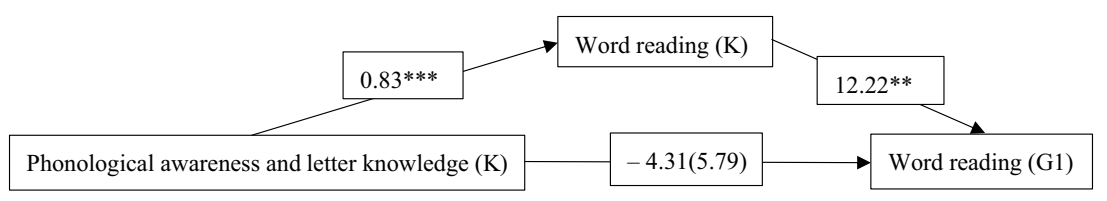

Fig. 2 Mediation model of kindergarten phonological awareness and letter knowledge, kindergarten word reading, and grade 1 word reading in Dutch. The total effect (c) is between brackets, outside the brackets are the direct effects $\left(c^{\prime}\right)$. The factor scores of phonological awareness and letter knowledge were used in the analysis. The model is significant, $\mathrm{R}^{2}=.17, F(2,38)=3.78, p<.05$. The indirect effect of kindergarten phonological awareness and letter knowledge on Grade 1 word reading via kindergarten word reading was $10.10,(\mathrm{CI}[1.29,22.31]) . * p<.05, * * p<.01$, *** $p<.001$ 
Table 5 Hierarchical regression explaining Chinese (L1) word reading in kindergarten and grade 1 from Dutch (L2) kindergarten word reading after controlling for Chinese kindergarten precursors

\begin{tabular}{|c|c|c|c|c|c|c|}
\hline Step & Predictors $(\mathrm{K})$ & $\Delta \mathrm{R}^{2}$ & Cohen's $\mathrm{f}^{2}$ & $\mathrm{~B}$ & SE & $\beta$ \\
\hline \multicolumn{7}{|c|}{ L1 word reading $(\mathrm{K})$} \\
\hline \multirow[t]{4}{*}{1} & L1 Phonological awareness & $.42 * * *$ & .72 & 28 & .13 & $.34^{*}$ \\
\hline & RAN & & & .01 & .01 & .18 \\
\hline & STM & & & .06 & .06 & .13 \\
\hline & Visual skills & & & .03 & .02 & .22 \\
\hline \multirow[t]{5}{*}{2} & L1 Phonological awareness & .01 & .02 & .25 & .13 & .31 \\
\hline & RAN & & & .01 & .01 & .20 \\
\hline & STM & & & .05 & .06 & .11 \\
\hline & Visual skills & & & .03 & .02 & .18 \\
\hline & L2 Word reading & & & .08 & .11 & .11 \\
\hline \multicolumn{4}{|c|}{ Total $R^{2}$ adj } & & & $.35 * * *$ \\
\hline \multicolumn{7}{|c|}{ L1 word reading (G1) } \\
\hline \multirow[t]{4}{*}{1} & L1 Phonological awareness & .20 & .25 & 4.65 & 2.24 & $.38^{*}$ \\
\hline & RAN & & & -.02 & .18 & -.02 \\
\hline & STM & & & 1.38 & 1.11 & .21 \\
\hline & Visual skills & & & -.08 & .36 & -.04 \\
\hline \multirow[t]{5}{*}{2} & L1 Phonological awareness & .003 & .004 & 4.88 & 2.35 & $.39 *$ \\
\hline & RAN & & & -.03 & .19 & -.03 \\
\hline & STM & & & 1.44 & 1.14 & .22 \\
\hline & Visual skills & & & -.04 & .38 & -.02 \\
\hline & L2 Word reading & & & -.72 & 1.91 & -.07 \\
\hline \multicolumn{4}{|c|}{ Total $R^{2}$ adj } & & & .09 \\
\hline
\end{tabular}

$* p<.05 ; * * p<.01 ; * * * p<.001$

reading in the second step did not significantly improve the model, $\Delta \mathrm{R}^{2}=0.003, F$ $(1,35)=0.14, p=0.71$.

\section{Discussion}

\section{Summary of findings}

The present study investigated the role of predictors (phonological awareness, RAN, STM, letter knowledge, and visual skills) in early reading concurrently and longitudinally among 41 Chinese-Dutch bilingual kindergarten children in the Netherlands. Both word reading in L1 and L2 was predicted from phonological awareness in kindergarten. Dutch word reading was additionally predicted by letter knowledge. A robust autoregressive effect of word reading from kindergarten to first grade was found in Chinese and Dutch. Moreover, it was evidenced that phonological awareness in kindergarten had a significant indirect effect on Grade 
1 reading ability through this ability in kindergarten in Chinese. The indirect effect of phonological awareness and letter knowledge on first grade word reading via kindergarten word reading was found in Dutch. A cross-language correlation between Chinese and Dutch word reading was found in kindergarten. However, Dutch word reading did not add to the prediction of Chinese word reading after controlling for Chinese reading-related skills in both concurrent and longitudinal models. These findings are discussed below.

With regard to the association between phonological awareness, RAN, STM, visual skills, and word reading in Chinese in kindergarten, we found that Chinese phonological awareness was the unique predictor of word reading. It supports again the idea of a robust effect of phonological awareness on emergent Chinese reading, which was in line with past studies on monolingual Chinese children (e.g., Shu et al., 2008) and bilingual Chinese-English children (e.g., Chow et al., 2005).

Secondly, RAN did not uniquely predict Chinese word reading in kindergarten. Past studies showed that RAN predicted Chinese reading not only for monolingual Chinese children (e.g., Li et al., 2012) but also for Hong Kong children who learned English as a second language in kindergarten (e.g., Chow et al., 2005), whereas this was not shown in the present study. A possible explanation is that these studies used rapid number naming instead of rapid object naming as we did in the present study. Graphological RAN tasks (such as number-naming) tend to be more strongly associated with literacy skills than nongraphological RAN tasks (such as object-naming) (Georgiou et al., 2008; Song et al., 2016). Another explanation could come from the early reading stage of bilingual children. As past studies suggested, each Chinese character is a distinct visual referent and recognized as a whole or part to whole. More skilled Chinese readers start to treat Chinese compound characters as single units (Liao et al., 2008), thus accurate and efficient access to the lexicon is increasingly important for Chinese reading (Liao et al., 2008; Shu \& Anderson, 1997). RAN does capture this automaticity of orthographic processing in Chinese reading because it refers to the ability to name highly familiar visual stimuli. However, the bilingual children in the present study were in the very primary stage of Chinese reading. They had a smaller Chinese vocabulary size and lower reading level compared with their peers in Mainland China, and tend to decode characters primarily via their phonological representations rather than by orthographic representations (e.g., Chen, 2003; Shu \& Anderson, 1997). This could also be proved by the finding that phonological awareness was a unique predictor of Chinese reading. The fact that word reading accuracy, rather than fluency, was tested in Chinese could be an additional explanation.

Thirdly, STM was not salient. Very few past studies have examined the relationship between STM and Chinese reading, and STM has not always been a unique predictor of reading. For example, the findings of Chow et al. (2005) showed that for Chinese-English kindergarten children in Hong Kong, STM did not predict Chinese word reading. A similar result was found by Yang et al. (2019). Xue et al. (2013) showed that STM contributed to Grade 4 character naming but not to Grade 2 or 6 in Mainland China. Combined with the finding in the present study, it seems likely that among the three phonological processing skills, STM does not have a similar robust 
predictive role of Chinese word reading in both monolingual and bilingual children as other skills.

Our study further showed that visual skills did not predict Chinese word reading in kindergarten. This is in contrast to Tong et al. (2011), who followed kindergarten children aged 4-6 in Hong Kong for two years and did find that visual spatial relationships uniquely predicted Chinese word reading across time. The reason could be the early start of formal literacy education for children in Hong Kong. While children in Hong Kong receive systematic formal literacy education from kindergarten, Chinese bilingual children receive it much later in the Netherlands. Thus the stage at which visual skills affected word reading may appear later for children in the present study compared with Hong Kong children.

Pinyin did not significantly correlate with Chinese word reading at the two measurement time points. This finding can be explained by a floor effect in children, as the mean score of this task was only 1.46 out of 47 . The reason was that children had not received formal Chinese literacy education. It would be interesting to reexamine this relationship in older bilingual Chinese-Dutch children.

With respect to Dutch word reading, phonological awareness and letter knowledge predicted word reading in kindergarten. In other words, our finding highlighted that phonological awareness and letter knowledge were important for emergent Dutch word reading in bilingual children. This was consistent with the finding from Verhoeven et al. (2016), showing that the emergence of word decoding was predicted from phonological awareness among Dutch kindergarten monolingual children. The finding of a strong impact of letter knowledge on Dutch initial word reading was not surprising, as Dutch is a transparent language. Letter-sound correspondence has a robust effect on word reading. Previous studies also demonstrated that monolingual children could learn to read by processing letter-sound relations in words before formal reading instruction has started (Cardoso-Martins et al., 2002; De Abreu \& Cardoso-Martins, 1998; Verhoeven et al., 2016) and a stronger prediction of word reading by grapheme-phoneme knowledge for L2 learners (Schaars et al., 2019).

It should be noted that phonological awareness in Chinese and Dutch involved unparallel tasks. Choosing unparallel versions for phonological awareness in the present study apparently has advantages. An important aspect of Chinese phonological awareness, tone awareness, is included. The different tasks used in the present study have been elaborately shown to be important for word reading in Chinese and Dutch (Chinese: McBride-Chang et al., 2008; Li et al., 2012; Shu et al., 2008; Dutch: De Jong, \& Van der Leij, 1999; Verhoeven et al., 2016; Schaars et al., 2017). However, it may also have disadvantages. The involvement of tone awareness in the Chinese version and the phoneme segmentation in the Dutch version makes the concept of phonological awareness in Chinese and Dutch diverse. In future research, this should be further examined.

The finding that RAN and STM were not unique predictors of Dutch word reading contrasts with previous studies (Aarnoutse et al., 2005; De Jong, \& Van der Leij, 1999; Schaars et al., 2019). The absence of an effect of RAN and STM could be due to its high relationship with phonological awareness and letter knowledge $(\mathrm{r}=0.59$ and 0.63$)$, thus sharing common variance explaining Dutch word reading. 
The present study provided more evidence that access to phonological representations and grapheme-phoneme knowledge is critical for learning to read for bilingual children. Visual skills did not predict Dutch kindergarten word reading, which corresponded with our hypothesis. Reading in alphabetic languages relied on grasping the principle of letter-sound correspondence rather than distinguishing the character components.

For both L1 and L2, results on the word reading development indicated strong autoregressive effects, which means that the development of word reading from kindergarten to primary school for bilingual children was highly stable. The study of Verhoeven and van Leeuwe (2012) and the study of Schaars et al. (2019) found that individual differences in children's word reading which occur at the beginning of reading instruction prevail across grades for children who learned Dutch as a second language in primary school. Our study extended this strong longitudinal effect in the development of reading earlier, from kindergarten and extended to a bilingual group with two languages in different structures. It is also keeping with the results of a study on French-English bilingual children from Gottardo and Lafrance (2005). Kindergarten reading performance was the only predictor of word reading in first grade in L2. However, Gottardo and Lafrance additionally found that kindergarten phonological awareness and RAN predicted L1 word reading in Grade 1 after kindergarten word reading was controlled for. In contrast, we found kindergarten word reading as the only unique predictor of L1 (Chinese) reading in first grade. This could be explained by the nature of the L1 orthography. The complexity of Chinese reading development may set a higher demand on children's previous reading foundation. A past study in Hong Kong children also found that Grade 1 word reading predicted Grade 2 and Grade 2 word reading predicted Grade 4 word reading (Yeung et al., 2012). It can then be concluded that the longitudinal predictive patterns from kindergarten to first grade for bilingual children depended on their linguistic properties.

It is also interesting to note that although similar prediction patterns occur with kindergarten word reading as a significant predictor of later word reading for both L1 and L2, this skill explained far more variance in word reading in first grade for L1. This might be attributed to the different educational stages in Chinese and Dutch. Children in the present sample received formal literacy education in Dutch from the beginning of first grade while they did not receive it in Chinese meanwhile. Therefore, Chinese word reading development remained more stable than Dutch word reading development. The variance accounted for Dutch word reading may come from other reading-related skills because of receiving Dutch formal literacy education.

We further found that the direct contribution of kindergarten phonological skills (phonological awareness in Chinese, phonological awareness and letter knowledge in Dutch) to the prediction of kindergarten word reading and the indirect impact of this ability through kindergarten word reading to word reading in first grade in both L1 and L2. This suggests that phonological skills continue to contribute to word reading development across time. It is possible that the instructional method used in L2 strengthens the use of phonological skills in the process of learning to read L1. Children in the present study gradually grasp the principles of phonological recoding via 
storybook reading and language games in the Dutch literacy environment. According to the interdependence hypothesis, reading instruction in one language not only leads to literacy skills in that language, but also to a deeper conceptual and linguistic proficiency, which is strongly related to literacy and general academic skill in the other language (Cummins, 1981). This can be verified from the correlation table that Chinese kindergarten word reading significantly correlated with all the Dutch kindergarten variables ( $\mathrm{r}$ was from 0.33 to 0.37 ). Evidence was also provided by past studies showing the strong correlations between Chinese and English phonological awareness, and word reading (e.g., Wang et al., 2005). Therefore, exposure to a second transparent language may highlight the association between phonological awareness and word reading in L1 for Chinese-Dutch bilingual children.

\section{Cross-language transfer of reading ability}

A significant cross-language of correlation between Chinese and Dutch word reading was found $(r=0.33)$ in kindergarten but not in first grade. Dutch word reading did not add to the prediction of Chinese word reading in kindergarten or first grade after controlling for Chinese reading-related skills.

The finding that there was a correlation in kindergarten could be explained by the fact that the children in the present study had not received any formal literacy education in kindergarten. It is possible that overlap in reading strategies between Chinese and Dutch strengthens the cross-language connection of word reading skills for children in the prereading stage.

The lack of a correlation between Chinese and Dutch word reading in first grade is in line with studies that did not find strong associations between the two languages among bilingual Chinese-English children in English-speaking contexts (Gottardo et al., 2001; Pasquarella et al., 2015; Wang et al., 2005). The explanation could be found in the instructional method the children received (Pasquarella et al., 2015). Children in these studies were in English learning environments and received formal English literacy education from primary school. The instructional method may strengthen the use of reading strategies in that language to learn other languages. Therefore, after children received literacy education in Dutch from first grade, this strong cross-language connection disappeared.

The lack of prediction from Dutch word reading to Chinese word reading was in line with the study from Pasquarella et al. (2015). They examined the cross-language transfer of word reading accuracy in Spanish-English and Chinese-English bilingual children. English word reading did not contribute unique variance to Chinese word reading after the relevant skills were controlled. In contrast, English word reading accuracy was a unique predictor of Spanish word reading accuracy. Structural similarities in L1 and L2 facilitate the cross-language transfer of word reading while script differences may not. Our study provided evidence of a cross-language association but not a cross-language prediction between Chinese and Dutch word reading. However, it should be noted that we used an accuracy measure for Chinese word reading, while we used a fluency measure for Dutch word reading. We used accuracy-fluency word reading task in Dutch because Dutch has a consistent orthography 
(Verhoeven \& van Leeuwe, 2012). Previous studies provided clear evidence that learning to read is easier in consistent orthographies than in opaque orthographies. There is a rapid growth spurt as soon as reading instruction begins (e.g., Caravolas et al., 2013). In the present study, considering children receive Dutch formal literacy from first grade, to reserve more variation, character reading accuracy is more suitable to reflect Chinese word reading ability and word reading fluency is more suitable to reflect Dutch word reading ability for the present samples.

To our knowledge, this was the first study to empirically investigate the development of early literacy acquisition in bilingual Chinese-Dutch children. It expands understanding of learning to read of bilingual children who speak two structurally different languages. The findings presented evidence of somewhat different precursors in L1 and L2 kindergarten reading performance while similar longitudinal predictive patterns of reading. It also showed that cross-language transfer of word reading may be limited in bilingual children who speak very different languages.

\section{Limitations and future directions}

The present study has a limitation regarding sample size. The relatively small number of Chinese immigrants in the Netherlands and the fact that data can only be collected on Sunday schools with very limited testing time per weekend made it difficult to include a large number of participants. Our study should thus be seen as a first step in investigating the processes of learning to read of bilingual ChineseDutch children. Future research with larger sample sizes is recommended. Another limitation is that we only measured language exposure at home and the educational levels of parents. More details of family background need to be taken into account in future research, such as the economic status of parents. A final limitation is the low reliability of tone awareness, which could be explained by the "yes or no" questions. Open-ended methods can be used in future research to increase the reliability.

\section{Educational implications and conclusions}

The findings of the current study have some practical implications. The high stability of individual differences in word reading development in both L1 and L2 confirms that more attention can be paid to word reading skills even before children receive formal literacy education. Also, this can be a way to avoid the possible risk of lagging literacy development in bilingual children. The finding of cross-language correlation between L1 and L2 implies that Chinese reading and Dutch reading were related to each other. Teachers can instruct bilingual children to apply their word reading knowledge to support learning to read another language.

To sum up, our study is the first longitudinal study examining the predictive patterns of Chinese-Dutch bilingual children from kindergarten to first grade. We showed that phonological skills continue to play a role in word reading in L1 and L2, with a direct effect on word reading before children receiving formal literacy education and an indirect effect on subsequent word reading through kindergarten 
word reading. In addition, it underscored that the previous reading level was an essential foundation for reading development in Chinese and Dutch. More evidence was provided that cross-language transfer of word reading is limited among bilingual children speaking structurally different languages.

Acknowledgements This research was supported by China scholarship council (201608340056).

Open Access This article is licensed under a Creative Commons Attribution 4.0 International License, which permits use, sharing, adaptation, distribution and reproduction in any medium or format, as long as you give appropriate credit to the original author(s) and the source, provide a link to the Creative Commons licence, and indicate if changes were made. The images or other third party material in this article are included in the article's Creative Commons licence, unless indicated otherwise in a credit line to the material. If material is not included in the article's Creative Commons licence and your intended use is not permitted by statutory regulation or exceeds the permitted use, you will need to obtain permission directly from the copyright holder. To view a copy of this licence, visit http://creativecommons.org/licen ses/by/4.0/.

\section{References}

Aarnoutse, C., van Leeuwe, J., \& Verhoeven, L. (2005). Early literacy from a longitudinal perspective. Educational Research and Evaluation, 11, 253-275. https://doi.org/10.1080/08993400500101054

Araújo, S., Reis, A., Petersson, K. M., \& Faísca, L. (2015). Rapid automatized naming and reading performance: A meta-analysis. Journal of Educational Psychology, 107, 868-883. https://doi.org/10. 1037/edu0000006

August, D. E., \& Shanahan, T. E. (2006). Developing literacy in second-language learners: Report of the National Literacy Panel on Language-Minority Children and Youth. Lawrence Erlbaum Associates Publishers.

Byrne, B., \& Fielding-Barnsley, R. (1989). Phonemic awareness and letter knowledge in the child's acquisition of the alphabetic principle. Journal of Educational Psychology, 81, 313.

Caravolas, M., Lervåg, A., Mikulajová, M., Defior, S., Seidlová-Málková, G., \& Hulme, C. (2019). A cross-linguistic, longitudinal study of the foundations of decoding and reading comprehension ability. Scientific Studies of Reading, 23, 386-402. https://doi.org/10.1080/10888438.2019.1580284

Caravolas, M., Lervåg, A., Defior, S., Seidlová Málková, G., \& Hulme, C. (2013). Different patterns, but equivalent predictors, of growth in reading in consistent and inconsistent orthographies. Psychological Science, 24(8), 1398-1407. https://doi.org/10.1177/0956797612473122.

Cardoso-Martins, C., Resende, S. M., \& Rodrigues, L. A. (2002). Letter name knowledge and the ability to learn to read by processing letter-phoneme relations in words: Evidence from Brazilian Portuguese-speaking children. Reading and Writing: An Interdisciplinary Journal, 15, 409-432. https:// doi.org/10.1023/A:1015213514722

Chen, M. J. (2003). Component skills for reading Chinese in primary school children. In C. McBrideChang \& H.-C. Chen (Eds.), Reading development in Chinese children (pp. 19-33). Praeger.

Chen, X., \& Pasquarella, A. (2017). Learning to read Chinese. In L. Verhoeven \& C. Perfetti (Eds.), Learning to read across languages and writing systems, (pp. 31-56). Cambridge: Cambridge University Press. https://doi.org/10.1017/9781316155752.002

Cheung, H., Chung, K. K. H., Wong, S. W. L., McBride-Chang, C., Penney, T. B., \& Ho, C. S. H. (2010). Speech perception, metalinguistic awareness, reading, and vocabulary in Chinese-English bilingual children. Journal of Educational Psychology, 102, 367-380. https://doi.org/10.1037/a0017850

Chiappe, P., Glaeser, B., \& Ferko, D. (2007). Speech perception, vocabulary, and the development of reading skills in English among Korean-and English-speaking children. Journal of Educational Psychology, 99, 154-166. https://doi.org/10.1037/0022-0663.99.1.154

Chow, B. W. Y., McBride-Chang, C., \& Burgess, S. (2005). Phonological processing skills and early reading abilities in Hong Kong Chinese kindergarteners learning to read English as a second language. Journal of Educational Psychology, 97, 81-87. 
Cummins, J. (1981). The role of primary language development in promoting educational success for language minority students. In California State Department of Education (Ed.), Schooling and language minority students: A theoretical rationale (pp. 3-49). Los Angeles, CA: California State University.

De Abreu, M. D., \& Cardoso-Martins, C. (1998). Alphabetic access route in beginning reading acquisition in Portuguese: The role of letter-name knowledge. Reading and Writing: An Interdisciplinary Journal, 10, 85-104. https://doi.org/10.1023/A:1007939610145

De Jong, P. F., \& Van der Leij, A. (1999). Specific contributions of phonological abilities to early reading acquisition: Results from a Dutch latent variable longitudinal study. Journal of Educational Psychology, 91, 450-476. https://doi.org/10.1037/0022-0663.91.3.450

Dressler, C., \& Kamil, M. L. (2006). First-and second-language literacy. In D. August \& T. Shanahan (Eds.), Developing literacy in second language learners: A report of the National Literacy Panel on Language-Minority Children and Youth (pp. 197-238). Lawrence Erlbaum Associates Publishers.

Dunn, L. M., Dunn, L. M., \& Schlichting, J. E. P. T. (2005). Peabody picture vocabulary test-III-NL. Harcourt Test Publishers.

Ehri, L. C. (2005). Learning to read words: Theory, findings, and issues. Scientific Studies of Reading, 9, 167-188. https://doi.org/10.1207/s1532799xssr09024

Franceschini, S., Gori, S., Ruffino, M., Pedrolli, K., \& Facoetti, A. (2012). A causal link between visual spatial attention and reading acquisition. Current Biology, 22, 814-819. https://doi.org/10.1016/j. cub.2012.03.013

Gardner, M. F. (1996). Test of visual-perceptual skills (Non-motor): Revised manual. Hydesville, CA: Psychological and Educational Publications.

Georgiou, G. K., Parrila, R., \& Liao, C. H. (2008). Rapid naming speed and reading across languages that vary in orthographic consistency. Reading and Writing: An Interdisciplinary Journal, 21, 885-903. https://doi.org/10.1007/s11145-007-9096-4

Georgiou, G. K., Torppa, M., Manolitsis, G., Lyytinen, H., \& Parrila, R. (2012). Longitudinal predictors of reading and spelling across languages varying in orthographic consistency. Reading and Writing: An Interdisciplinary Journal, 25, 321-346. https://doi.org/10.1007/s11145-010-9271-X

Gottardo, A., \& Lafrance, A. (2005). A longitudinal study of phonological processing skills and reading in bilingual children. Applied Psycholinguistics, 26, 559-578. https://doi.org/10.1017/S014271640 5050307

Gottardo, A., Yan, B., Siegel, L. S., \& Wade-Woolley, L. (2001). Factors related to English reading performance in children with Chinese as a first language: More evidence of cross-language transfer of phonological processing. Journal of Educational Psychology, 93, 530.

Hayes, A. F. (2017). Introduction to mediation, moderation, and conditional process analysis: A regression-based approach. Guilford Publications.

Hu, C. F., \& Catts, H. W. (1998). The role of phonological processing in early reading ability: What we can learn from Chinese. Scientific Studies of Reading, 2, 55-79. https://doi.org/10.1207/s1532799xs sr0201_3

Hutcheson, G., \& Sofroniou, N. (1999) The multivariate social scientist: Introductory statistics using generalized linear models. Thousand Oaks, CA: Sage Publication. https://doi.org/10.4135/97808 57028075

Indefrey, P. (2006). A meta-analysis of hemodynamic studies on first and second language processing: Which suggested differences can we trust and what do they mean? Language Learning, 56, 279304. https://doi.org/10.1111/j.1467-9922.2006.00365.x

Jongejan, W., Verhoeven, L., \& Siegel, L. S. (2007). Predictors of reading and spelling abilities in firstand second-language learners. Journal of Educational Psychology, 99, 835-851. https://doi.org/10. 1037/0022-0663.99.4.835

Keung, Y. C., \& Ho, C. S. H. (2009). Transfer of reading-related cognitive skills in learning to read Chinese (L1) and English (L2) among Chinese elementary school children. Contemporary Educational Psychology, 34, 103-112. https://doi.org/10.1016/j.cedpsych.2008.11.001

Li, H., Shu, H., McBride-Chang, C., Liu, H., \& Peng, H. (2012). Chinese children's character recognition: Visuo-orthographic, phonological processing and morphological skills. Journal of Research in Reading, 35, 287-307. https://doi.org/10.1111/j.1467-9817.2010.01460.x

Li, W. L., Jiang, W., Shu, H., Hong, T., \& Anderson, R. (2016). The role of Pinyin in Chinese reading development. In L. W. Li \& H. Shu (Eds.), The world of children's reading (pp. 3-26). Beijing Normal University Press. 
Liao, C. H., Georgiou, G. K., \& Parrila, R. (2008). Rapid naming speed and Chinese character recognition. Reading and Writing: An Interdisciplinary Journal, 21, 231-253. https://doi.org/10.1007/ s11145-007-9071-0

Lin, C. Y., Cheng, C., \& Wang, M. (2018). The contribution of phonological and morphological awareness in Chinese-English bilingual reading acquisition. Reading and Writing: An Interdisciplinary Journal, 31, 99-132. https://doi.org/10.1007/s11145-017-9775-8

Lin, D., McBride-Chang, C., Shu, H., Zhang, Y., Li, H., Zhang, J., Aram, D., \& Levin, I. (2010). Small wins big: Analytic Pinyin skills promote Chinese word reading. Psychological Science, 21, 11171122. https://doi.org/10.1177/0956797610375447

Lu, L., \& Liu, H. S. (1998). The Peabody picture vocabulary test-revised in Chinese. Psychological Publishing.

Luo, Y. C., Chen, X., Deacon, S. H., Zhang, J., \& Yin, L. (2013). The role of visual processing in learning to read Chinese characters. Scientific Studies of Reading, 17, 22-40. https://doi.org/10.1080/ 10888438.2012.689790

Luo, Y. C., Chen, X., \& Geva, E. (2014). Concurrent and longitudinal cross-linguistic transfer of phonological awareness and morphological awareness in Chinese-English bilingual children. Written Language \& Literacy, 17, 89-115. https://doi.org/10.1075/wll.17.1.05luo

McBride-Chang, C., Chow, B. W., Zhong, Y., Burgess, S., \& Hayward, W. G. (2005). Chinese character acquisition and visual skills in two Chinese scripts. Reading and Writing: An Interdisciplinary Journal, 18, 99-128. https://doi.org/10.1007/s11145-004-7343-5

McBride-Chang, C., \& Ho, C. S. H. (2000). Developmental issues in Chinese children's character recognition. Journal of Educational Psychology, 92, 50-55. https://doi.org/10.1037/0022-0663. 92.1.50

McBride-Chang, C., \& Kail, R. V. (2002). Cross-cultural similarities in the predictors of reading acquisition. Child Development, 73, 1392-1407. https://doi.org/10.1111/1467-8624.00479

McBride-Chang, C., \& Suk-Han Ho, C. (2005). Predictors of beginning reading in Chinese and English: A 2-year longitudinal study of Chinese kindergartners. Scientific Studies of Reading, 9, 117-144. https://doi.org/10.1207/s1532799xssr0902_2

McBride-Chang, C., Tong, X., Shu, H., Wong, A. M. Y., Leung, K. W., \& Tardif, T. (2008). Syllable, phoneme, and tone: Psycholinguistic units in early Chinese and English word recognition. Scientific Studies of Reading, 12, 171-194. https://doi.org/10.1080/10888430801917290

Melby-Lervåg, M., \& Lervåg, A. (2011). Cross-linguistic transfer of oral language, decoding, phonological awareness and reading comprehension: A meta-analysis of the correlational evidence. Journal of Research in Reading, 34, 114-135. https://doi.org/10.1111/j.1467-9817.2010.01477.x

Melby-Lervåg, M., Lyster, S. A. H., \& Hulme, C. (2012). Phonological skills and their role in learning to read: A meta-analytic review. Psychological Bulletin, 138, 322-352. https://doi.org/10. 1037/a0026744

Moelands, F., Kamphuis, F., \& Rymenans, R. (2003). Drie-minuten-toets voor vlaanderen (DMT-V): Wetenschappelijke verantwoording [Three-Minutes-Test for Flanders (DMT-V): scientific justification]. Arnhem, Netherlands: Citogroep.

Muthén, L. K., \& Muthén, B. O. (2007). Mplus User's Guide (5th ed.). Los Angeles, CA: Muthén \& Muthén.

Páez, M., \& Rinaldi, C. (2006). Predicting English word reading skills for Spanish-speaking students in first grade. Topics in Language Disorders, 26, 338-350. https://doi.org/10.1097/00011363200610000-00006

Pan, J., McBride-Chang, C., Shu, H., Liu, H., Zhang, Y., \& Li, H. (2011). What is in the naming? A 5-year longitudinal study of early rapid naming and phonological sensitivity in relation to subsequent reading skills in both native Chinese and English as a second language. Journal of Educational Psychology, 103, 897-908. https://doi.org/10.1037/a0024344

Pasquarella, A., Chen, X., Gottardo, A., \& Geva, E. (2015). Cross-language transfer of word reading accuracy and word reading fluency in Spanish-English and Chinese-English bilinguals: Scriptuniversal and script-specific processes. Journal of Educational Psychology, 107, 96-110. https:// doi.org/10.1037/a0036966

Patel, T. K., Snowling, M. J., \& de Jong, P. F. (2004). A cross-linguistic comparison of children learning to read in English and Dutch. Journal of Educational Psychology, 96, 785-797. https://doi. org/10.1037/0022-0663.96.4.785 
Schaars, M. M., Segers, E., \& Verhoeven, L. (2017). Word decoding development in incremental phonics instruction in a transparent orthography. Reading and Writing: An Interdisciplinary Journal, 30, 1529-1550. https://doi.org/10.1007/s11145-017-9735-3

Schaars, M. M., Segers, E., \& Verhoeven, L. (2019). Cognitive and linguistic precursors of early first and second language reading development. Learning and Individual Differences, 72, 1-14. https://doi.org/10.1016/j.lindif.2019.03.008

Shu, H., \& Anderson, R. C. (1997). Role of radical awareness in the character and word acquisition of Chinese children. Reading Research Quarterly, 32, 78-89. https://doi.org/10.1598/RRQ.32.1.5

Shu, H., Peng, H., \& McBride-Chang, C. (2008). Phonological awareness in young Chinese children. Developmental Science, 11, 171-181. https://doi.org/10.1111/j.1467-7687.2007.00654.x

Song, S., Georgiou, G. K., Su, M., \& Hua, S. (2016). How well do phonological awareness and rapid automatized naming correlate with Chinese reading accuracy and fluency? A meta-analysis. Scientific Studies of Reading, 20, 99-123. https://doi.org/10.1080/10888438.2015.1088543

Swanson, H. L., \& Ashbaker, M. (2000). Working memory, STM, articulation speed, word recognition, and reading comprehension in learning disabled readers: Executive and/or articulatory system. Intelligence, 28, 1-30.

Swanson, H. L., Orosco, M. J., Lussier, C. M., Gerber, M. M., \& Guzman-Orth, D. A. (2011). The influence of working memory and phonological processing on English language learner children's bilingual reading and language acquisition. Journal of Educational Psychology, 103, 838856. https://doi.org/10.1037/a0024578

Swanson, H. L., Sáez, L., Gerber, M., \& Leafstedt, J. (2004). Literacy and cognitive functioning in bilingual and nonbilingual children at or not at risk for reading disabilities. Journal of Educational Psychology, 96, 3-18. https://doi.org/10.1037/0022-0663.96.1.3

Swanson, H. L., Trainin, G., Necoechea, D. M., \& Hammill, D. D. (2003). Rapid naming, phonological awareness, and reading: A meta-analysis of the correlation evidence. Review of Educational Research, 73, 407-440. https://doi.org/10.3102/00346543073004407

Tong, X., McBride-Chang, C., Wong, A. M. Y., Shu, H., Reitsma, P., \& Rispens, J. (2011). Longitudinal predictors of very early Chinese literacy acquisition. Journal of Research in Reading, 34, 315-332. https://doi.org/10.1111/j.1467-9817.2009.01426.x

Van den Bos, K. P., \& Lutje Spelberg, H. C. (2007). Continu Benoemen \& Woorden Lezen. Een test voor het diagnosticeren van taal-en leesstoornissen [Continuously Naming \& Reading Words. A test for diagnosing language and reading disorders]. Boom Test Publishers.

van der Schuit, M., Segers, E., van Balkom, H., \& Verhoeven, L. (2011). How cognitive factors affect language development in children with intellectual disabilities. Research in Developmental Disabilities, 32, 1884-1894. https://doi.org/10.1016/j.ridd.2011.03.015

Verhoeven L. (1995). Leerlingvolgsysteem: Drie-Minuten-Toets [Three Minutes Test]. Arnhem: CITO (Centraal instituut voor toetsontwikkeling).

Verhoeven, L. (2011). Ethnic minority children acquiring literacy. Walter de Gruyter.

Verhoeven, L., Cain, K., Compton, D. L., \& Parrila, R. K. (2017). Learning to read in a second language. Theories of reading development. John Benjamin.

Verhoeven, L., \& Van Kuyk, J. J. (1991). Peiling van conceptuele en metalinguïstische kennis bij de aanvang van het basisonderwijs [Assessment of conceptual and metalinguistic knowledge at the entrance of kindergarten]. Pedagogische Studiën, 68, 415-425.

Verhoeven, L., \& Van Leeuwe, J. (2012). The simple view of second language reading throughout the primary grades. Reading and Writing: An Interdisciplinary Journal, 25, 1805-1818. https://doi.org/ 10.1007/s11145-011-9346-3

Verhoeven, L., van Leeuwe, J., Irausquin, R., \& Segers, E. (2016). The unique role of lexical accessibility in predicting kindergarten emergent literacy. Reading and Writing: An Interdisciplinary Journal, 29, 591-608. https://doi.org/10.1007/s11145-015-9614-8

Wagner, R. K., \& Torgesen, J. K. (1987). The nature of phonological processing and its causal role in the acquisition of reading skills. Psychological Bulletin, 101(2), 192.

Wang M., Lin C. Y., Yang C. (2014a). Contributions of phonology, orthography, and morphology in chinese-english biliteracy acquisition: a one-year longitudinal study. In X. Chen, Q. Wang, \& Y. Luo (Eds.), Reading development and difficulties in monolingual and bilingual chinese children. Literacy studies (perspectives from cognitive neurosciences, linguistics, psychology and education), vol 8. Springer, Dordrecht. https://doi.org/10.1007/978-94-007-7380-6_10

Wang, M., Perfetti, C. A., \& Liu, Y. (2005). Chinese-English biliteracy acquisition: Cross-language and writing system transfer. Cognition, 97, 67-88. https://doi.org/10.1016/j.cognition.2004.10.001 
Wang, Y., McBride-Chang, C., \& Chan, S. F. (2014b). Correlates of Chinese kindergarteners' word reading and writing: The unique role of copying skills? Reading and Writing: An Interdisciplinary Journal, 27, 1281-1302. https://doi.org/10.1007/s11145-013-9486-8

Wei, W., Georgiou, G. K., \& Deng, C. (2015). Examining the cross-lagged relationships between RAN and word reading in Chinese. Scientific Studies of Reading, 19, 446-455. https://doi.org/10.1080/ 10888438.2015.1077447

Wimmer, H., Mayringer, H., \& Landerl, K. (2000). The double-deficit hypothesis and difficulties in learning to read a regular orthography. Journal of Educational Psychology, 92, 668. https://doi.org/10. 1037/0022-0663.92.4.668

Xue, J., Shu, H., Li, H., Li, W., \& Tian, X. (2013). The stability of literacy-related cognitive contributions to Chinese character naming and reading fluency. Journal of Psycholinguistic Research, 42, 433-450. https://doi.org/10.1007/s10936-012-9228-0

Yang, L. Y., Guo, J. P., Richman, L. C., Schmidt, F. L., Gerken, K. C., \& Ding, Y. (2013). Visual skills and Chinese reading acquisition: A meta-analysis of correlation evidence. Educational Psychology Review, 25, 115-143. https://doi.org/10.1007/s10648-013-9217-3

Yang, M., Cooc, N., \& Sheng, L. (2017). An investigation of cross-linguistic transfer between Chinese and English: A meta-analysis. Asian-Pacific Journal of Second and Foreign Language Education, 2, 15. https://doi.org/10.1186/s40862-017-0036-9

Yang, X., McBride, C., Ho, C. S. H., \& Chung, K. K. H. (2019). Longitudinal associations of phonological processing skills, Chinese word reading, and arithmetic. Reading and Writing: An Interdisciplinary Journal, 33, 1679-1699. https://doi.org/10.1007/s11145-019-09998-9

Yeong, S. H., Fletcher, J., \& Bayliss, D. M. (2014). Importance of phonological and orthographic skills for English reading and spelling: A comparison of English monolingual and Mandarin-English bilingual children. Journal of Educational Psychology, 106, 1107-1121. https://doi.org/10.1037/ a0036927

Yeung, P. S., Ho, C. S. H., Chik, P. P. M., Lo, L. Y., Luan, H., Chan, D. W. O., \& Chung, K. K. H. (2011). Reading and spelling Chinese among beginning readers: What skills make a difference? Scientific Studies of Reading, 15, 285-313. https://doi.org/10.1080/10888438.2010.482149

Yeung, P. S., Ho, C. S. H., Wong, Y. K., Chan, D. W. O., Chung, K. K., \& Lo, L. Y. (2012). Longitudinal predictors of Chinese word reading and spelling among elementary grade students. Applied Psycholinguistics, 34, 1245-1277. https://doi.org/10.1017/S0142716412000239

Yeung, S. S., \& Chan, C. K. (2013). Phonological awareness and oral language proficiency in learning to read English among Chinese kindergarten children in Hong Kong. British Journal of Educational Psychology, 83, 550-568. https://doi.org/10.1111/j.2044-8279.2012.02082.x

Zhao, Y., Cheng, Y., \& Wu, X. (2019). Contributions of morphological awareness and rapid automatized naming (RAN) to Chinese children's reading comprehension versus reading fluency: Evidence from a longitudinal mediation model. Reading and Writing: An Interdisciplinary Journal, 32, 2013-2036. https://doi.org/10.1007/s11145-019-09935-w

Publisher's Note Springer Nature remains neutral with regard to jurisdictional claims in published maps and institutional affiliations. 